\title{
Inquérito sorológico e molecular da brucelose canina no município de Natal, Estado do Rio Grande do Norte
}

\author{
Serological and molecular survey of canine brucellosis in the county of Natal, \\ Rio Grande do Norte state
}

\author{
Annielle Regina da Fonseca Fernandes ${ }^{\mathrm{I}}$ Ademilde Gomes Fernandes ${ }^{\mathrm{II}}$ Tereza Emmanuelle de \\ Farias Rotondano ${ }^{\mathrm{III}}$ Clebert José Alves ${ }^{\mathrm{I}}$ Pomy de Cássia Peixoto Kim ${ }^{\mathrm{IV}}$ \\ Rinaldo Aparecido Mota ${ }^{\mathrm{IV}}$ Sérgio Santos de Azevedo ${ }^{\mathrm{I} *}$
}

\section{RESUMO}

O objetivo do presente trabalho foi determinar a ocorrência de anticorpos anti-Brucella rugosa e anti-Brucella lisa em cães do município de Natal, Estado do Rio Grande do Norte, Brasil, bem como identificar fatores de risco associados à positividade e realizar a detecção molecular em animais soropositivos. Foram utilizados soros sanguíneos de 416 cães atendidos em clínicas veterinárias durante o período de março a novembro de 2011. Para o diagnóstico sorológico da infeç̧ão por Brucella rugosa, foi empregada a prova de imunodifusão em gel de ágar (IDGA), utilizando antígeno de lipopolissacarídeos e proteínas de Brucella ovis, amostra Reo 198 e, para o diagnóstico da infecção por Brucella lisa, foi utilizado o teste do antígeno acidificado tamponado (AAT). De animais soropositivos, foram coletadas amostras de sangue com citrato de sódio para o diagnóstico pela reação em cadeia pela polimerase (PCR). A frequência de anticorpos anti-Brucella rugosa foi de 28,9\% (120/416). Todos os animais foram negativos para anticorpos anti-Brucella lisa. Dentre 80 animais soropositivos, o DNA de Brucella spp. foi amplificado em três animais (3,8\%). Não foram identificados fatores de risco associados à soropositividade. Conclui-se que a infecção por Brucella rugosa está presente no município de Natal, bem como se sugere o monitoramento sorológico de animais atendidos em clínicas visando à identificação de fontes de infecção.

Palavras-chave: brucelose canina, cães, IDGA, PCR, Brasil.

\section{ABSTRACT}

The aim of this study was to determine the occurrence of anti-rough Brucella and anti-smooth Brucella antibodies in dogs from the county of Natal, Rio Grande do Norte state, Brazil, as well as to identify risk factors associated with positivity and to perform molecular detection of the agent in seropositive animals. Sera from 416 dogs attended in veterinary clinics during the period from March to November 2011 were used. For the serological diagnosis of rough Brucella the agar gel immunodiffusion (AGID) test, using antigen of lipopolysaccharides and proteins from Brucella ovis, strain Reo 198, was carried, and for smooth Brucella the buffered plate agglutination test (BPAT) was used. From seropositive animals, blood samples with sodium citrate were collected for the diagnosis by polymerase chain reaction (PCR). Frequency of anti-rough Brucella antibodies was 28.9\% (120/416). All animals were negative for anti-smooth Brucella antibodies. Of the 80 seropositive animals Brucella spp. DNA was amplified in three (3.8\%). Risk factors associated with the seropositivity were not identified. It was concluded that rough Brucella infection is present in the county of Natal, as well as it is suggested the serological monitoring of animals attended at clinics aiming the identification of sources of infection.

Key words: canine brucellosis, cães, IDGA, PCR, Brazil.

\section{INTRODUÇÃO}

A brucelose é uma das principais doenças infectocontagiosas de caráter reprodutivo em cães, causada pela Brucella canis, responsável por sérias alterações, culminando geralmente em infertilidade. Nas fêmeas, predominam os abortamentos, natimortos ou nascimento de filhotes fracos, além de orquite e epididimite nos machos, tendo, portanto, uma relevante importância para os criadores de cães de raça (JOHNSON \& WALKER, 1992; WANKE, 2004). Devido ao papel que os animais de companhia

IUnidade Acadêmica de Medicina Veterinária (UAMV), Centro de Saúde e Tecnologia Rural (CSTR), Universidade Federal de Campina Grande (UFCG), Av. Universitária s/n, Bairro Santa Cecília, 58700-970, Patos, PB, Brasil. E-mail: ssazevedo@cstr.ufcg.edu.br. * Autor para correspondência.

IIClínica Veterinária SOS Animais, Natal, RN, Brasil.

IIIUniversidade Federal de Pernambuco, Recife, PE, Brasil.

IV Universidade Federal Rural de Pernambuco, Recife, PE, Brasil. 
representam para a sociedade, em especial os cães, com um convívio cada vez mais estreito e prolongado com seres humanos, deve-se considerar o caráter zoonótico dessa infecção, fato esse comprovado por vários relatos de casos clínicos e estudos de prevalência de anticorpos anti-B. canis em humanos (LUCERO et al., 2005; VOSS, 2008).

Somente com o exame clínico não é possível chegar ao diagnóstico da infecção, podendo ser grande o número de animais que permanecem assintomáticos, atuando como importantes fontes de infecção (KEID et al., 2004). Em função da dificuldade e da baixa especificidade do diagnóstico clínico, a confirmação da brucelose canina deve ser realizada por métodos laboratoriais indiretos e diretos, pela detecção de anticorpos séricos, isolamento bacteriano ou métodos moleculares (MINHARRO et al., 2005). O isolamento e a identificação da $\boldsymbol{B}$. canis é um método de alta especificidade diagnóstica, pois demonstra o agente etiológico da doença, mas sua sensibilidade pode ser baixa em decorrência de vários fatores, como eliminação intermitente da bactéria, material mal colhido e mal conservado, além da utilização de antibióticos. Além disso, essa prova requer um período prolongado de tempo até a identificação do agente e laboratórios de biossegurança de nível 3, o que limita sua implementação (LARA et al., 2007). Dessa forma, os testes sorológicos, representados pelas provas de soroaglutinação lenta e rápida, e a imunodifusão em gel de agarose (IDGA) são os métodos frequentemente utilizados no diagnóstico da doença (PORTO et al., 2008). Os métodos de amplificação de DNA, como a reação em cadeia pela polimerase (PCR), têm demonstrado ser confirmatórios no diagnóstico de brucelose, permitindo encurtar o tempo de diagnóstico, reduzir os riscos de exposição e simplificar os requisitos de infraestrutura necessários (KEID et al., 2009; OLIVEIRA et al., 2011).

Desse modo, devido à escassez de estudos no Estado do Rio Grande do Norte, particularmente no Município de Natal, e à relevância da doença como zoonose, objetivou-se, com este trabalho, determinar a frequência de anticorpos anti-Brucella rugosa $e$ anti-Brucella lisa em cães do referido município, bem como identificar os fatores de risco associados à soropositividade e realizar detecção molecular em animais soropositivos.

\section{MATERIAL E MÉTODOS}

A pesquisa foi realizada no município de Natal, capital do Estado do Rio Grande do Norte.
Foram utilizados 416 cães com idade acima de três meses que passaram pelo atendimento de 10 clínicas particulares, localizadas em vários pontos da cidade (Figura 1), durante o período de março a novembro de 2011. Não foram utilizados critérios probabilísticos para a seleção das clínicas e dos animais, sendo baseada na concordância dos proprietários.

As coletas de sangue foram efetuadas por punção nas veias cefálica ou jugular externa, utilizando-se seringas descartáveis de $5 \mathrm{~mL}$, com posterior obtenção do soro e estocagem a $-20^{\circ} \mathrm{C}$. Na ocasião da coleta de sangue, os proprietários dos cães responderam a um questionário epidemiológico, elaborado de modo a fornecer dados de variáveis (Tabela 2) a serem utilizadas na análise de fatores de risco para a brucelose canina.

Para o diagnóstico sorológico da infecção por Brucella rugosa, empregou-se a técnica de imunodifusão em gel de agar (IDGA), utilizandose kits produzidos pelo Instituto de Tecnologia do Paraná (TECPAR). A técnica foi executada de acordo com as recomendações do fabricante, utilizando-se antígeno de lipopolissacarídeos e proteínas de $\boldsymbol{B}$. ovis, amostra Reo 198. Para a pesquisa de anticorpos anti-Brucella lisa, o teste do Antígeno Acidificado Tamponado (AAT) foi utilizado (BRASIL, 2001).

Quatro meses após a coleta de sangue para sorologia, os animais considerados positivos foram novamente localizados para coleta de sangue com anticoagulante (citrato de sódio) e realização do diagnóstico pela reação em cadeia pela polimerase (PCR). As amostras tiveram seu DNA extraído através da utilização do kit comercial DNeasy Blood and Tissue (Qiagen - USA). O DNA obtido foi armazenado a $-20^{\circ} \mathrm{C}$ até o momento da amplificação. Para a reação, foram utilizados os primers ITS66 (ACATAGATCGCAGGCCAGTCA) e ITS279 (AGATACCGACGCAAACGCTAC) (KEID et al., 2007), os quais amplificam uma sequência de $214 \mathrm{pb}$ e são específicos para bactérias do gênero Brucella. A amplificação das amostras de DNA foi realizada em microtubos de $200 \mu \mathrm{L}$, com volume final de $12,5 \mu \mathrm{L}$, em que foi utilizado $0.5 \mu \mathrm{M}$ de cada primer e uma solução pré-misturada, contendo $200 \mu \mathrm{M}$ dNTP, 1,5mM MgCl2, 5U Taq DNA polymerase (Taq PCR Master Mix - QIAGEN/USA) e 2,5 $\mu \mathrm{L}$ de DNA (DNA genômico na concentração média de 200ng $\mu \mathrm{l}^{-1}$ ). Como controle negativo, foi utilizada água ultrapura, enquanto que a amostra 63/290 de B. ovis foi empregada como controle positivo. No ciclo empregado, inicialmente, as amostras foram submetidas a uma desnaturação de $95^{\circ} \mathrm{C}$ por 2 minutos 


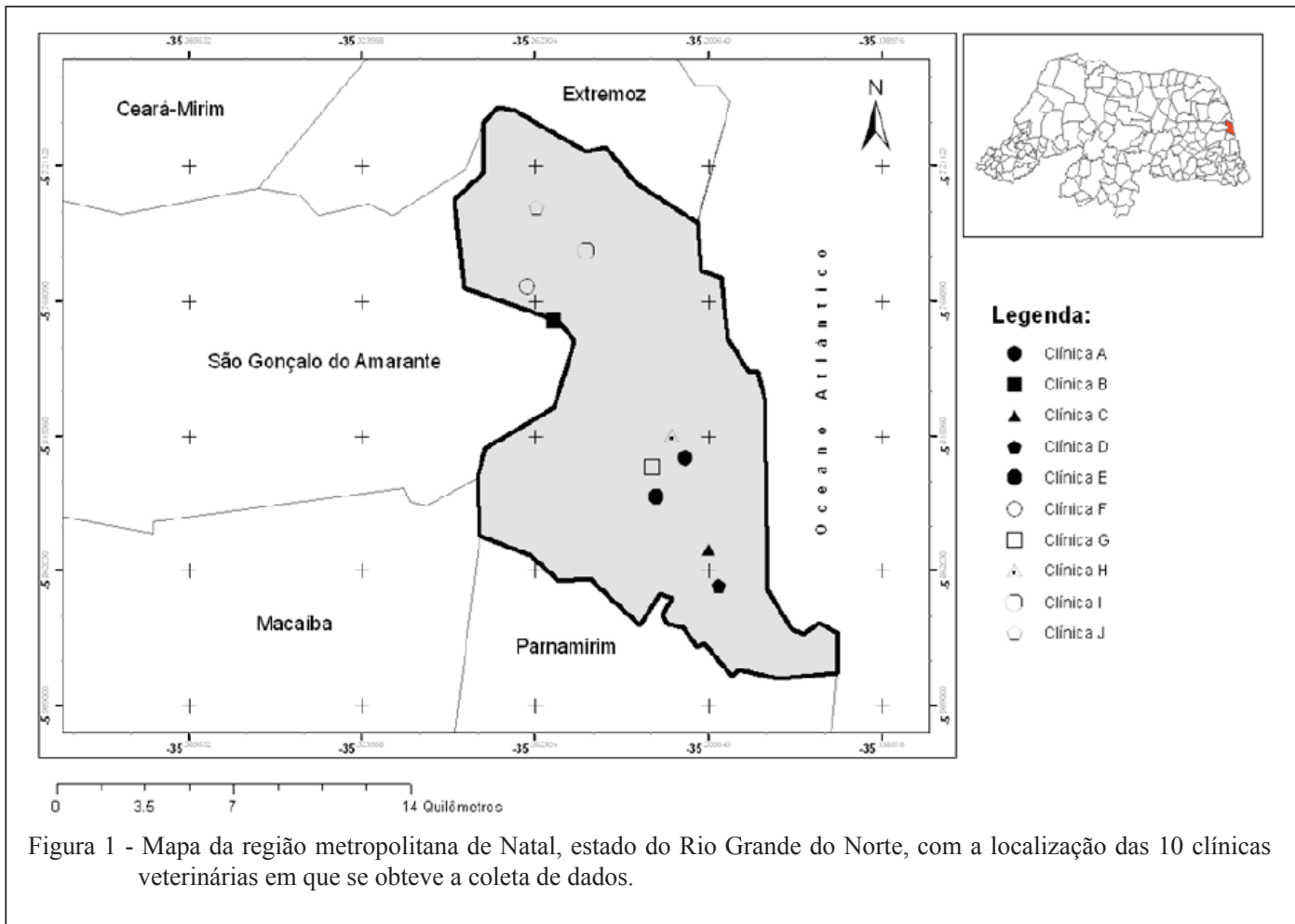

e, a seguir, empregados 40 ciclos de amplificação, divididos em quatro fases: Desnaturação: $95^{\circ} \mathrm{C}$ 130 segundos; Anelamento: $62^{\circ} \mathrm{C} / 30$ segundos; Extensão: $72^{\circ} \mathrm{C} / 30$ segundos; e Extensão final: $72^{\circ} \mathrm{C} / 5$ minutos. A análise do produto amplificado foi realizada por eletroforese em gel de agarose a 2,0\%, com tampão de corrida TBE $0,5 \mathrm{X}(0,045 \mathrm{M}$ TRIS-Borato e $1 \mathrm{mM}$ de EDTA, pH 8,0) e o gel submetido à voltagem constante de $6-7 \mathrm{~V} / \mathrm{cm}$. O padrão de peso molecular empregado foi de $100 \mathrm{pb}$ (Fermentas). As amostras para o gel foram coradas com Blue Green (LGC Biotecnologia, Brasil) e, posteriormente, fotografado sob luz ultravioleta pelo sistema de foto-documentação (Câmera Kodak Digital DC/120 Zoom).

A análise de possíveis fatores de risco associados à soropositividade foi efetuada em duas etapas: análise univariável e análise multivariável. $\mathrm{Na}$ análise univariável, foram formados dois grupos de animais - soropositivos e soronegativos -, que foram comparados frente às variáveis analisadas. Aquelas variáveis que apresentaram valor de $P \leq 0,2$ pelo teste de qui-quadrado ou teste exato de Fisher foram selecionadas para a análise multivariável, utilizando-se o método de seleção stepwise forward de regressão logística múltipla. O nível de significância adotado foi de $5 \%$ e as análises foram realizadas com o programa SPSS 20.0 for Windows.

\section{RESULTADOS E DISCUSSÃO}

Dos 416 animais analisados pela prova da IDGA, 120 foram soropositivos, correspondendo a uma frequência de $28,9 \%$. Em todas as clínicas, houve pelo menos um animal positivo, com frequência de soropositividade variando de $8,8 \%$ a $42,3 \%$ (Tabela 1). Esse percentual de positividade foi inferior aos resultados obtidos por VARGAS et al. (1996) em Santa Maria, RS, NÁREZ et al. (1999) na cidade do México, MEGID et al. (1999) em Botucatu, SP, MOLNÁR et al. (2001) em Belém, PA, e JIANG et al. (2012) em Pequim, na China, que obtiveram $72,7 \%, 45 \%, 57,1 \%$, $45,4 \%$, e $48,8 \%$ de positividade, respectivamente. Esses resultados podem ser explicados pelo fato de esses estudos, com exceção dos dois últimos, terem sido realizados em canis comerciais, que possuíam um histórico de infertilidade, abortamentos e casos de natimortos, sendo um ambiente altamente favorável para a difusão da infecção, devido às condições de confinamento dos animais, favorecendo a transmissão da bactéria, pelo fato de haver um contato íntimo de animais doentes e sadios. No presente trabalho, foram examinadas amostras de animais que não apresentavam histórico de problemas reprodutivos que poderiam ser sugestivos de brucelose canina.

Todos os animais foram negativos para anticorpos anti-Brucella lisa. Isso pode ser 
Tabela 1 - Frequência de anticorpos anti-Brucella rugosa de acordo com a clínica veterinária e sua localização em 416 cães do município de Natal, Rio Grande do Norte, no período de março a novembro de 2011.

\begin{tabular}{lccc}
\hline Clínicas veterinárias & № de animais utilizados & $\mathrm{N}^{\mathrm{o}}$ de animais positivos (\%) & Localização \\
\hline $\mathrm{A}$ & 123 & $52(42,3)$ & Zona sul \\
$\mathrm{B}$ & 52 & $13(25,0)$ & Zona sul \\
$\mathrm{C}$ & 49 & $18(36,7)$ & Zona sul \\
$\mathrm{D}$ & 35 & $6(17,1)$ & Zona oeste \\
$\mathrm{E}$ & 11 & $1(9,1)$ & Zona leste \\
$\mathrm{F}$ & 6 & $1(16,7)$ & Zona norte \\
$\mathrm{G}$ & 84 & $21(25,0)$ & Zona norte \\
$\mathrm{H}$ & 34 & $3(8,8)$ & Zona norte \\
$\mathrm{I}$ & 10 & $1(10,0)$ & Zona norte \\
$\mathrm{J}$ & 12 & $4(33,3)$ & - \\
\hline
\end{tabular}

justificado pelo fato de ter sido utilizada população de cães urbanos, uma vez que a infecção natural de cães por brucelas lisas, especialmente B. abortus, é de ocorrência esporádica e resulta do contato estreito de cães, geralmente de zona rural, com bovinos infectados. Os cães infectam-se por ingestão de produtos de origem animal in natura, contato ou ingestão de tecidos animais, restos placentários ou de fetos abortados contaminados (CARMICHAEL \& GREENE, 1998; AZEVEDO et al., 2003). Essa espécie parece ser mais resistente à infecção por brucelas lisas, sendo raras as manifestações clínicas decorrentes da infecção (AZEVEDO et al., 2003).

Dos 120 animais soropositivos, 80 foram localizados, dos quais foi feita coleta de sangue para detecção molecular do agente. Nenhum animal apresentou sintomatologia sugestiva de brucelose canina. A frequência de amplificação de DNA pela PCR nesses animais foi de 3,8\% (3/80). Essa discrepância entre animais soropositivos e detecção molecular do agente pode ser explicada pelo fato de a bacteremia, na brucelose canina, apesar de prolongada, passa a ser intermitente e eventualmente diminuir em infecções crônicas (JOHNSON \& WALKER, 1992). Além disso, na prova sorológica empregada, foram utilizados antígenos de superfície bacteriana, compostos por lipopolissacarídeos (LPS) e proteínas de membrana externa. Testes baseados em antígenos de superfície são mais utilizados como provas de triagem e apresentam alta sensibilidade no diagnóstico da brucelose canina. No entanto, esses antígenos também são compartilhados com outras bactérias, como Moraxella sp., Pseudomonas aeruginosa, Staphylococcus sp. e Bordetella bronchiseptica, resultando na ocorrência de reações cruzadas (JOHNSON \& WALKER, 1992; CARMICHAEL \& GREENE, 1998).

De acordo com CARMICHAEL \& GREENE (1998) e MEGID et al. (1999), em geral, enquanto há persistência da bacteremia, os títulos de anticorpos anti-LPS permanecem elevados. Com o passar do tempo, a tendência é de que ocorra redução nos títulos de anticorpos séricos, de modo que os animais permanecem com títulos baixos ou até mesmo sorologicamente negativos. No entanto, pode haver ainda uma flutuação nos títulos de anticorpos, tanto na presença quanto na ausência de bacteremia. Apesar de delineamentos diferentes do presente estudo, SALGADO et al. (2008) e KEID et al. (2009) também corroboraram o fato de que os testes sorológicos devem ser cuidadosamente utilizados como testes de triagem e que a associação entre métodos diretos e indiretos norteia a melhoria na sensibilidade relativa do teste sorológico, quando comparado com o seu uso individual, sugerindo que essa relação deve ser aplicada no diagnóstico da doença.

$\mathrm{Na}$ análise univariável para os fatores de risco, as variáveis selecionadas foram tipo de criação, contato com outros animais e passear com os cães 
Tabela 2 - Análise univariada para fatores de risco associados com a soropositividade para Brucella rugosa em 416 cães do município de Natal, Rio Grande do Norte, no período de março a novembro de 2011.

\begin{tabular}{|c|c|c|c|c|}
\hline Variável & Categoria & № total de animais & $\mathrm{N}^{\circ}$ de animais soropositivos $(\%)$ & $P$ \\
\hline \multirow{6}{*}{ Escolaridade do proprietário } & $1^{\circ} \mathrm{Grau}$ incompleto & 2 & $0(0)$ & \\
\hline & $1^{\circ}$ Grau completo & 3 & $2(66,7)$ & \\
\hline & $2^{\circ}$ Grau incompleto & 13 & $3(23,1)$ & \\
\hline & $2^{\circ}$ Grau completo & 181 & $48(26,5)$ & \\
\hline & $3^{\circ}$ Grau incompleto & 23 & $7(30,4)$ & \\
\hline & $3^{\circ}$ Grau completo & 194 & $60(30,9)$ & 0,545 \\
\hline \multirow{2}{*}{ Sexo dos animais } & Macho & 192 & $49(25,5)$ & \\
\hline & Fêmea & 224 & $71(31,7)$ & 0,201 \\
\hline \multirow{4}{*}{ Idade dos animais } & $3-12$ meses & 48 & $17(35,4)$ & \\
\hline & $13-48$ meses & 147 & $41(27,9)$ & \\
\hline & $49-72$ meses & 63 & $19(30,2)$ & \\
\hline & $>72$ meses & 158 & $43(27,2)$ & 0,721 \\
\hline \multirow{2}{*}{ Raça } & Sem raça definida & 101 & $30(29,7)$ & \\
\hline & Com raça definida & 315 & $90(28,6)$ & 0,927 \\
\hline \multirow{3}{*}{ Tipo de criação } & Domiciliar & 372 & $113(30,4)$ & \\
\hline & Semi-domiciliar & 38 & $6(15,8)$ & \\
\hline & Solto & 6 & $1(16,7)$ & $0,134 *$ \\
\hline \multirow{3}{*}{ Alimentação } & Ração comercial & 261 & $77(29,5)$ & \\
\hline & Comida caseira & 13 & $2(15,4)$ & \\
\hline & Ração+comida caseira & 142 & $41(28,9)$ & 0,548 \\
\hline \multirow{2}{*}{ Contato com outros animais } & Não & 186 & $46(24,7)$ & \\
\hline & Sim & 230 & $74(32,2)$ & $0,119 *$ \\
\hline \multirow{2}{*}{ Contato com animais silvestres } & Não & 392 & $112(28,6)$ & \\
\hline & Sim & 24 & $8(33,3)$ & 0,789 \\
\hline \multirow{3}{*}{ Ambiente dos cães } & Terra & 14 & $6(42,9)$ & \\
\hline & Cimento & 231 & $61(26,4)$ & \\
\hline & Terra+Cimento & 171 & $53(31,0)$ & 0,302 \\
\hline \multirow{2}{*}{ Limpeza do ambiente dos cães } & Não & 5 & $1(20,0)$ & \\
\hline & Sim & 411 & $119(29,0)$ & 1,000 \\
\hline \multirow{2}{*}{ Vacinação } & Não & 31 & $6(19,4)$ & \\
\hline & Sim & 385 & $114(29,6)$ & 0,314 \\
\hline \multirow{2}{*}{ Passear com os cães } & Não & 206 & $51(24,8)$ & \\
\hline & $\operatorname{Sim}$ & 210 & $69(32,9)$ & $0,086^{*}$ \\
\hline \multirow{2}{*}{ Viajar com os cães } & Não & 345 & $97(28,1)$ & \\
\hline & Sim & 71 & $23(32,4)$ & 0,561 \\
\hline
\end{tabular}

* Variáveis selecionadas para a regressão logística múltipla $(P \leq 0,2)$. 
(Tabela 2). No entanto, não foram identificados fatores de risco na análise multivariável. Embora não tenham sido identificados fatores de risco para a infecção por Brucella rugosa, algumas variáveis merecem ser destacadas como a idade e a raça dos animais.

Considerando a idade dos animais, verificou-se que $85,8 \%$ (103/120) dos animais positivos tinham mais de um ano de idade. Resultado similar foi observado por AZEVEDO et al. (2003) e FERNANDES et al. (2011), que encontraram maior proporção de resultados positivos em animais com idade superior a um ano. Isso pode ser justificado pela maturidade sexual e consequente cobertura, bem como pela maior possibilidade de contato com animais infectados em função da idade (JOHNSON \& WALKER, 1992; CARMICHAEL \& GREENE, 1998). Além disso, ainda de acordo com JOHNSON \& WALKER (1992), animais impúberes podem adquirir a infecção, pois, normalmente, a manifestação clínica é apenas uma linfadenopatia uni ou bilateral, enquanto que os sinais clínicos reprodutivos só se manifestam após a puberdade.

Analisando a raça, também não foi constatada associação com a ocorrência de soropositivos. No entanto, foi observado que $75 \%$ (90/120) dos animais positivos eram de raça definida. Quando das primeiras descrições de cães infectados por B. canis, os animais da raça Beagle foram considerados como os mais susceptíveis (MOORE, 1969). No entanto, posteriormente, a doença passou a ser diagnosticada em cães de raças diversas (CARMICHAEL \& KENNEY; 1968; FREDRICKSON \& BARTON, 1974). Vale salientar que grande parte dos animais do presente estudo eram de raça definida, e isso se deve à própria preferência de seus proprietários, que acabam por adquiri-los através de canis comerciais, pet shops e até mesmo de criações domiciliares informais. A prevenção da infecção é particularmente importante nesses lugares, pois, uma vez introduzida numa população confinada, a doença se dissemina rapidamente (KEID et al., 2004).

\section{CONCLUSÃO}

Os resultados apresentados indicam que a infecção por Brucella rugosa, detectada por sorologia e PCR, está presente em cães atendidos em clínicas veterinárias do município de Natal.. Embora não tenham sido identificados fatores de risco, sugere-se o monitoramento sorológico de animais atendidos, visando à identificação de fontes de infecção.

\section{COMITÊ DE ÉTICA E BIOSSEGURANÇA}

O referido trabalho foi aprovado pela Comissão de Ética no Uso de Animais (CEUA) da Faculdade de Ciências Médicas de Campina Grande, sob o número 0018/240712.

\section{REFERÊNCIAS}

AZEVEDO, S.S. et al. Inquérito sorológico e fatores de risco para a brucelose por Brucella canis em cães do município de Santana de Parnaíba, Estado de São Paulo. Pesquisa Veterinária Brasileira, v.23, p.156-160, 2003. Disponível em: <http://www.scielo.br/scielo. php?script $=$ sci_arttext\&pid $=\mathrm{S} 0100-36 \mathrm{X} 2003000400003>$. Acesso em: 02 out. 2012. doi: 10.1590/S0100-736X2003000400003.

BRASIL. Ministério da Agricultura, Pecuária e Abastecimento. Departamento de Defesa Animal. Programa Nacional de Controle e Erradicação da Brucelose e Tuberculose Animal (PNCEBT). Inquérito soroepidemiológico da brucelose - Manual de procedimentos. Brasília, 2001. 20p.

CARMICHAEL, L.E.; GREENE, C.E. Canine brucellosis. In: GREENE, C.E. Infectious diseases of the dog and cat. Philadelphia: Saunders, 1998. p.248-257.

CARMICHAEL, L.E.; KENNEY, R.M. Canine abortion caused by Brucella canis. Journal of the American Veterinary Medical Association, v.152, p.605-616, 1968.

FERNANDES, A.R.F. et al. Brucella canis infection in dogs attended in veterinary clinics from Patos, Paraíba state, Brazil. Brazilian Journal of Microbiology, v.42, p.1405-1408, 2011. Disponível em: <http://www.scielo.br/scielo.php?pid=S1517$83822011000400023 \&$ script=sci_arttext $>$. Acesso em: 23 set. 2012. doi: 10.1590/S1517-83822011000400023.

FREDRICKSON, L.E.; BARTON, C.E. A serologic survey for canine brucellosis in a metropolitan area. Journal of the American Veterinary Medical Association, v.11, p.987-989, 1974.

JIANG, H. et al. Reemergence and genetic comparison of Brucella canis in China, using a multiple-locus variable-number tandemrepeat assay. Veterinary Microbiology, v.154, p.419-421, 2012. Disponível em: <http://www.sciencedirect.com/science/article/pii/ S037811351100410X>. Acesso em: 20 set. 2012. doi: 10.1016/j. vetmic.2011.07.014.

JOHNSON, C.A.; WALKER, R.D. Clinical signs and diagnosis of Brucella canis infection. Compendium on Continuing Education for the Practicing Veterinarian: Small Animal, v.14, p.763-772, 1992.

KEID, L.B. et al. Brucella spp. isolation from dogs from commercial breeding kennels in São Paulo state, Brazil. Brazilian Journal of Microbiology, v.35, n.1-2, p.161-166, 2004. Disponível em: $<$ http://www.scielo.br/scielo.php?script=sci_arttext\&pid $=\mathrm{s} 1517-83822004000100027>$. Acesso em: 12 out. 2012. doi: $10.1590 / \mathrm{S} 1517-83822004000100027$.

KEID, L.B. et al. Comparison of agar gel immunodiffusion test, rapid slide agglutination test, microbiological culture and PCR for the diagnosis of canine brucellosis. Research in Veterinary Science, v.86, p.22-26, 2009. Disponível em: <http://www.sciencedirect. com/science/article/pii/S0034528808001161>. Acesso em: 23 set. 2012. doi: 10.1016/j.rvsc.2008.05.012. 
KEID, L.B. et al. Diagnosis of canine brucellosis: comparison between serological and microbiological tests and a PCR based on primers to $16 \mathrm{~S}-23 \mathrm{~S}$ rDNA interspacer. Veterinary Research Communications, v.31, p.951-965, 2007. Disponível em: $<$ http://link.springer.com/article/10.1007\%2Fs11259-006-01096? LI=true $>$. Acesso em: 23 set. 2012. doi: 10.1007/s11259-0060109-6.

LARA, V.H.H. et al. Laboratorios de bioseguridad nivel 3 y 4 : investigación de patógenos peligrosos. Revista Mexicana de Patología Clínica, v.54, p.177-186, 2007.

LUCERO, N.E. et al. Diagnosis of human brucellosis caused by Brucella canis. Journal of Medical Microbiology, v.54, p.457461, 2005.

MEGID, J. et al. Epidemiological assessment of canine brucellosis. Arquivo Brasileiro de Medicina Veterinária e Zootecnia, v.51, p.439-440, 1999. Disponível em: $<$ http://www.scielo.br/scielo.php?script=sci arttext\&pid $=$ S0102-09351999000500007>. Acesso em: 10 set. 2012. doi: 10.1590/S0102-09351999000500007.

MINHARRO, S. et al. Diagnóstico da brucelose canina: dificuldades e estratégias. Revista Brasileira de Reprodução Animal, v.29, p.167-173, 2005.

MOLNÁR, L. et al. Capacidade de algumas provas sorológicas no diagnóstico de brucelose canina. A Hora Veterinária, v.21, p.45-49, 2001 .

MOORE, J.A. Brucella canis infection in dogs. Journal of the American Veterinary Medical Association, v.155, p.20342037, 1969.
NÁREZ, G.M. et al. Seguimiento de un brote de Brucella canis en un criadero de perros en la ciudad de Mexico. Técnica Pecuaria en México, v.37, p.43-50, 1999.

OLIVEIRA, M. et al. Identificación por PCR de Brucella canis en sangre y leche canina. Reporte de un caso. Archivos de Medicina Veterinaria, v.43,p.295-298,2011. Disponível em: <http://www.scielo. cl/scielo.php?pid=S0301-732X2011000300012\&script=sci_arttext $>$. Acesso em: 16 ago. 2012. doi: 10.4067/S0301-732X2011000300012.

PORTO, W.J.N. et al. Associação entre distúrbios reprodutivos anticorpos anti-Brucella sp em cães atendidos em clínicas particulares da cidade de Maceió-AL. Revista Brasileira de Ciência Veterinária, v.15, p.6-9, 2008.

SALGADO, V.R. et al. Evaluation of rapid slide agglutination test with and without 2-mercaptoetanol (2ME-RSAT and RSAT) and comparison with microbiological culture and Polimerase Chain Reaction (PCR) for the diagnosis of canine brucellosis. Biológico, v.70, p.107-216, 2008.

VARGAS, A.C. et al. Brucelose canina: relato de caso. Ciência Rural, v.26, p.305-308, 1996. Disponível em: <http://www.scielo.br/scielo. php?pid=S0103-84781996000200024\&script=sci_arttext $>$. Acesso em: 16 ago. 2012. doi: 10.1590/S0103-84781996000200024.

VOSS, C.R. Soroprevalência da brucelose canina para $\boldsymbol{B}$. canis e $\boldsymbol{B}$. abortus e avaliação sorológica dos humanos contactantes da cidade de Marília-SP. 2008. 81f. Dissertação (Mestrado em Medicina Veterinária) - Curso de Pós-graduação em Medicina Veterinária, Faculdade de Medicina Veterinária e Zootecnia, Universidade Estadual Paulista, SP.

WANKE, M.M. Canine brucellosis. Animal Reproduction Science, v.82/83, p.195-207, 2004. 